\title{
Indigenous Cotton Cloth of the Phu Thai Ethnic Group: Integration of Creative Economic Concepts in the Development of Production in Order to Create Added Economic Value
}

\author{
Jarunee Senarat ${ }^{1}$, Songkoon Chantachon ${ }^{1} \&$ Sastra Lao-Akka ${ }^{1}$ \\ ${ }^{1}$ The Faculty of Cultural Science, Mahasarakham University, Khamriang Sub-District, Kantarawichai District, \\ Maha Sarakham, Thailand \\ Correspondence: Jarunee Senarat, 21 Moo 2, Thong Thani Sub-district, Tawatburi District, Roi-Et Province \\ 45170, Thailand. E-mail: jarunee101@hotmail.com
}

Received: July 9, 2013 Accepted: September 5, 2013 Online Published: November 29, 2013

doi:10.5539/ass.v9n17p120

URL: http://dx.doi.org/10.5539/ass.v9n17p120

\begin{abstract}
Cloth products are vital to the inheritance of local and ethnic identity and wisdom in Thailand. Currently, the local cloth markets are struggling to keep up with global fashion trends and make an impact upon the new generations of Thai society that will continue their inheritance for the future. This research studies the background of indigenous cotton cloth products of the Phu Thai ethnic group and the current conditions of and problems with the production of indigenous cotton cloth products. The ultimate aim was to study the integration of creative economic concepts in the development of products in order to create added economic value. Study of six weaving groups in Northeastern Thailand found that the Phu Thai groups in Thailand brought their original dress culture with them when they emigrated from Laos. There are two characteristics of cotton cloth products: self-woven products for personal use and products woven as tradable community goods. However, within the Phu Thai group it is more popular for people to wear market-bought clothing and the production of cloth goods is becoming more commercialized, which is having detrimental effects on the inheritance of the handicraft. This research proposes a three-stage model of integration, covering creativity, investment and commercialization to provide a solution to the problems in developing production and ensuring that creative economic concepts are integrated to add economic value to the indigenous cotton cloth of the Phu Thai ethnic group.
\end{abstract}

Keywords: indigenous, cotton, cloth, Phu Thai, creative economy, added-value, development

\section{Background}

The creative economy is a system of economy that reveals production that combines culture, economy and technology. Nowadays, industries that use creative thinking are able to produce tangible and intangible value. These products concern creative thinking and have economic value and market targets that link existing bodies of knowledge (Panlamjiag \& Saengduean, 2011, p. 1). Indigenous cotton cloth is a valuable item that manufacturers may create in a number of different ways, such as by providing services to the customer by direct trade from the producer to the consumer in order to make things more convenient and save time in the travel time of the consumer. Aside from this, the creation of differences in the products concern their shape and form, such as style designs that are an identity of the producer, including the color and modernity of the cloth that is suitable for the consumer need. Currently, indigenous cotton cloth is popular among working people and is not only restricted to the elderly. Therefore the predictions or examinations of future consumer fashion trends can be combined with the abilities of local weavers by adding creative, innovative thinking and aspects of Thai identity onto the cotton cloth. This will make the production of cotton cloth stand out. Aside from this, the use of technology to assist in production will make standards for each production style and help the weavers achieve a higher production rate. This shows that differences and innovations in indigenous cotton cloth products enable the merchandise to compete on a level with other goods. For those indigenous products that reveal the local identity, it is especially necessary to create product diversity in order to create unique selling-points. A number of producers are supported by the government and private sector in the identification of a market and the sale of goods. It is popular for these producers to sell their wares in the same markets as traders of similar products. This makes it easier for the customer to compare the quality of products. Consequently, product diversification is important for goods of the same category (Mantamgarn, 1984, pp. 26-30). 
From these given conditions, the research team was interested in studying the conservation of indigenous cotton cloth of the Phu Thai ethnic group, which includes fibers, dyes, weaving, patterns and the development of design and marketing for indigenous cotton cloth production of the Phu Thai ethnic group. The ultimate objective was to study the integration of creative economic concepts in the development of production in order to create added economic value. It was aimed to create variety in the production of indigenous cotton cloth products of the Phu Thai ethnic group and widen and stabilize the market, so to add economic value as a method of conserving indigenous cloth weaving for the future. Additionally, this research was intended to start a development process for adapting existing bodies of knowledge and develop the form of products to increase community income and develop the quality of life and promote community economy.

\section{Research Aims}

This research had three research aims: a) to study the background of indigenous cotton cloth products of the Phu Thai ethnic group; b) to study the current conditions of and problems with the production of indigenous cotton cloth products of the Phu Thai ethnic group; c) to study the integration of creative economic concepts in the development of products in order to create added economic value.

\section{Research Methodology}

\subsection{Research Area}

This qualitative research was conducted in accordance with the main research objectives: to study the background, current conditions of and problems with the production of indigenous cotton cloth products of the Phu Thai ethnic group and to study the integration of creative economic concepts in the development of products in order to create added economic value. There were six locations used as part of the research area: a) Ban Phu Weaving Group, Ban Pao Sub-district, Nong Sung District, Mukdahan Province; b) Ban Khamcha-i Cotton Weaving Group, Khamcha-i Sub-district, Khamcha-i District Mukdahan Province; c) Ban Pone-sawan Weaving Group, Kut Sim Khum Mai Sub-district, Khao Wong District, Kalasin Province; d) Kok Gong Weaving Group, Kut Wa Sub-district, Kuchinarai District, Kalasin Province; e) Ban Kut Hai Weaving Group, Kut Hai Sub-district, Kut Bak District, Sakon Nakhon Province; f) Ban Bamuang Weaving Group, Kham Bo Sub-district, Waritchaphum District, Sakon Nakhon Province. The research population was comprised of eighty-eight individuals, separated into twenty-four key informants, forty-two casual informants and twenty-four general informants.

\subsection{Research Tools and Methodology}

Data collection was conducted by study of documents in six key categories: about Isan and Phu Thai culture and society; the body of knowledge about indigenous cotton cloth weaving of the Phu Thai ethnic group; laws and policies related to cloth weaving; the research context; related theories and concepts; and related research. The field research tools included community survey, interview, observation, focus-group discussion and workshop. These tools were used with the sample population of eighty-eight individuals, separated into twenty-four key informants, forty-two casual informants and twenty-four general informants. Data collection was carried out in accordance with the aims of the research and divided into two stages: document study and area survey; collection of field data using survey, interview, observation and focus-group discussion. Data analysis was conducted according to the research objectives and presented using related theories and concepts as a way of explaining the results according to the research aims. The presentation of results is a descriptive analysis.

\section{Research Results}

\subsection{The Background of Indigenous Cotton Cloth Products of the Phu Thai Ethnic Group}

The six research areas for this study were habitations of the Phu Thai ethnic group in Thailand. The interview of community experts regarding community background found that these communities had long histories of settlement in Thailand. Ban Phu Community, Ban Pao Sub-district, Nong Sung District, Mukdahan Province and Ban Khamcha-i Community, Khamcha-i Sub-district, Khamcha-i District Mukdahan Province emigrated from Laos in 1844. Ban Pone-sawan Community, Kut Sim Khum Mai Sub-district, Khao Wong District, Kalasin Province and Kok Gong Weaving Group, Kut Wa Sub-district, Kuchinarai District, Kalasin Province are also communities who came from Laos in the same year during the reign of King Rama III. The Phu Thai communities in Ban Kut Hai, Kut Hai Sub-district, Kut Bak District, Sakon Nakhon Province and Ban Bamuang Kham Bo Sub-district, Waritchaphum District, Sakon Nakhon both arrived from Laos during the reign of King Rama V in 1877.

The dress culture of Phu Thai is similar to the dress culture in their Laos origins. The first International Phu Thai Event in Kalasin Province allowed the Phu Thai communities to showcase their nature as an ethnic group. This 
event enabled the Phu Thai group to promote and conserve their own identity and culture, as well as create links to other Phu Thai groups and provide an opportunity for tourists to experience and appreciate their unique culture. The exhibition was open to Phu Thai communities for Laos, Vietnam and Thailand and the number of participants totaled ten thousand individuals.

Nowadays, there are two characteristics of cotton cloth products: self-woven products for personal use and products woven as tradable community goods. However, within the Phu Thai group it is more popular for people to wear market-bought clothing. This is different from the past, when the majority of Phu Thai people wove their own products for personal use. From the research areas studied, there were six visible categories of product created using the cotton cloth of the Phu Thai group, which are: female clothing, female accessories, home decorative accessories, male clothing, male accessories and souvenirs.

4.2 The Current Conditions of and Problems with the Production of Indigenous Cotton Cloth Products of the Phu Thai Ethnic Group

\subsubsection{Current Conditions}

Cotton is the original material used by the Phu Thai ethnic group in their weaving production. Survey, interview, observation and focus-group discussion in the six research areas was divided into three areas of focus from the beginning of production to final sale. The findings from these areas are illustrated in the table below (Table 1). 
Table 1. The current conditions of the production of indigenous cotton cloth products of the Phu Thai ethnic group

Production

There are two methods of fiber production, which are fibers created by the producer and factory-bought fibers. Production that uses self-created fibers reduce the start-up production costs of cotton cloth production and have a more beneficial effect on the

Production of Fiber community economy. Each year, fifty to one hundred kilograms of cotton are purchased from outside the area at a cost ranging from seventy to one-hundred and eighty baht per kilogram. If the cotton is purchased in retails markets, the cost is higher than if it is purchased directly. 108,000 to 300,000 baht is spent each year on cotton purchase to boost the insufficient stocks of community-produced cotton.

Natural dyes developed by the Phu Thai ethnic group come from the knowledge used by ancestors. These dyes come from parts of the surrounding environment to produce

Color Dyes

Cloth Patterns

Product Transformation different colors and shades, such as alum, lime water, red lime, ash, artesian well water and rust. There are a number of techniques used to infuse the dye with the material, such as boiling.

These reveal the concepts of social conditions in the group, including the fertility of the surrounding nature and the identity of the people. These patterns include frogs, Naga and birds and relate to the people in the society. The styles also reflect the beliefs and customs that have been inherited over time and are revealed on the Phu Thai sarongs. The Phu Thai style of sarong is short (above the knee) with a taper at the base, in contrast to the longer Thai styles. The styles are either established patterns, new innovations by the weaver or collective designs by the group.

\section{Product Transformation}

Product Design

Packaging Design

Product
Transformation
Process

Marketing

Customer

Capture

\section{Data}

Customer data is necessary for the development of woven products. There are four steps to the customer data capture: a) identification of customer groups-there were found to be four large groups of customers who bought woven products. These were culture groups (Phu Thai people and conservationist groups), government officers, youth, and general people; b) data collection method; c) customer care; d) data analysis to benefit production

Advertizing
Information and

Market

Business Network

The clothing designs for males and females are derived from local folk wisdom and the education of the weaving group. There are three types of product design within the weaving groups: new designs, adapted designs and imitated designs. There are four origins of the process of new design production: original group concepts, seminars, study and customer requests.

There are three forms of packaging for cotton cloth products of the Phu Thai ethnic group: paper bags, cardboard boxes and bamboo wickerwork.

There were three prominent types of product transformation in each of the studied provinces. In Mukdahan the three transformations are blankets with Orange Jessamine patterns, patterned shawls and kid-patterned breast-cloths. In Kalasin, the three transformations are hand-woven cotton clothes, cotton loincloths and four-heddle blankets. In Sakon Nakhon the three transformations are indigo-dyed sarongs, hand-woven indigo-dyed clothes and four-heddle blankets.

Past advertizing and information revealed very little and was insufficient and ineffective. Advertizing and information is currently provided by government institutions, universities and the internet.

There were found to be six types of sales market: a) direct from the Phu Thai weaving group; b) sales centers within the local community; c) trade stalls in the community; d) sale by the government sector; e) sale at market fairs; f) online sale.

There are three areas of business network. The first area is the network for raw materials. The second area is the network of basic cloth sale. The third area is the network of product sale at market fairs. 


\subsubsection{Problems}

The problems with indigenous cotton cloth products in the Phu Thai ethnic group can be divided into the same three categories as current conditions: production, product transformation and marketing. These problems are illustrated in the following table (Table 2).

Table 2. The problems with the production of indigenous cotton cloth products of the Phu Thai ethnic group

\section{Production}

Production of Fiber

Self-produced cotton requires long production times, large amounts of knowledge and strict observance of procedures and seasons. The consumer does not know which fibers are self-produced and which are factory-produced, causing inflated prices of factory produced fiber.

Color Dyes

Natural dyes are inconsistent due to the uncertain variables in producing the color. Aside from this, natural dyes are less durable than chemical dyes, yet customers prefer not to use chemical dyes due to their negative effect on the surrounding environment.

The weaving group members have differing levels of expertise in the knowledge of

Cloth Patterns patterns. Some patterns require long production times but this is not reflected in their market value.

\section{Product Transformation}

The designers were not always born in the local area and do not always live in the local area. This causes their designs to be incompatible with the abilities of the local weavers.

Product Design Thus, product development is not continuous. The product design ability of the group is not high, especially regarding complexities and modern trends. There are very few knowledge exchange seminars, affecting the level of knowledge of weavers.

The packaging is mostly supported by external institutions and, as such is not created in

Packaging Design the community. If the packaging is created by the local weavers, the sizes are not always uniform and the production of packaging cannot match demand.

The colors in the product transformation process are inconsistent. Some products are

Product

Transformation

Process

\section{Marketing}

The production process only allows for limited manufacture. As a result, many products are missing from the market. Also, the local communities have limited or non-existed consumer data collection methods.

\subsection{The Integration of Creative Economic Concepts in the Development of Products in Order to Create Added Economic Value}

The results of the focus-group discussion and the workshop enabled the integration of creative economic concepts in the development of products in order to create added economic value. The model of integration that corresponds to the current conditions and can solve the production problems of Phu Thai cotton cloth goods is divided into three stages: Creativity, Investment and Commercialization.

\subsubsection{Creativity}

The first stage of production is design and the weaving groups must have creative ability to use the materials available to them to add economic value to their products. Creativity must include consumer data study, product design and packaging design. Consumer data study includes observing the needs and requirements of the consumer. The Phu Thai groups must manage markets according to the tastes of their largest consumer base. At present, those people entering the community are people in education, students and teachers. The Phu Thai groups must create modern variations of their cotton cloth goods to appeal to the desires and requirements of these visitors, so that the market may provide it consumers with an attractive product. The weaving groups must improve their data collection methods concerning the problems noticed in each of the four consumer groups: 
culture groups (Phu Thai people and conservationist groups), government officers, youth, and general people.

As part of this model, there are six recommended steps for product design: a) survey of existing products; $b$ ) setting product specifications; c) preliminary design; d) analysis of product suitability; e) analysis of value; f) creation of a prototype. With regards the creation of packaging design, the four factors of product, usage instructions, trademark and appeal must be considered. There are five components of the packaging: inner packaging; outer packaging; usage instructions; trademark; and price.

\subsubsection{Investment}

Investment is the stage of transforming abstract ideas into concrete production. It is necessary for the creative ideas to be based upon real production possibilities. Therefore, it is necessary to generate capital for production, technology and factors related to production, especially with the experimentation of prototypes. It is also necessary for the weaving group to use people with expertise in finding sponsorship avenues and developing investment capital. This stage integrates fibers, dyes, patterns, weaving and product transformation. The process of adding economic value uses techniques and local folk wisdom. These are assisted by the observation of creative concepts and technology, using sewing to increase product durability.

\subsubsection{Commercialization}

The third stage is a continuation of investment in creative production. This is an extremely important stage as it familiarizes the consumer with the product. Market operations and the model of sale are important in accessing the customer and can also create added-value for indigenous cotton cloth products of the Phu Thai ethnic group. Nowadays, there is development of the marketing model and variety of product sale, especially by using advancements in technology and communication.

It was found that there is very little creation of business networks. Some weaving groups only know about sales events when the organizers inform them personally. They only have opportunity to promote their goods at these events. These problems make the income inconsistent and some members consider their earning potential to be minimal and choose to pursue other occupations. This has caused some groups to decrease membership. The six weaving groups specialize in different areas of product development: notebook bags, cases bags and file covers. However, it was revealed that the file covers were inappropriate for use, which stimulated concepts in net-book case design. This network is known as a businessman network, which has the objectives of promoting and creating cooperation and collaborating between business groups to strengthen the business. Cooperation includes data exchange, consultation and setting of cooperative agreements. These will strengthen the business group.

In order to solve problems with advertising and publicity, which included high costs and low use of media in advertising, there must be assistance and cooperation from the government sector. Previously, there was no weaving group that planned advertising and, for the most part, there was no advertising and publicity. The weaving groups are now increasing their levels of advertising by following two methods: increasing publicity and advertising in the existing markets and promoting advertising and publicity on the internet.

The problems with the market itself are that some groups are unable to sell their goods, the markets are infrequent and have little variation, profit gained from the markets is inadequate and prices differ between places of sale. There were found to be six types of sales market: a) direct from the Phu Thai weaving group; b) sales centers within the local community; c) trade stalls in the community; d) sale by the government sector; e) sale at market fairs; f) online sale. The integration of creative economic concepts in the development of cotton cloth products of the Phu Thai ethnic group in order to create added economic value requires the following processes: a) creativity, including market study, evaluation of skill and technology among weaving groups in production of cotton cloth groups, product design and packaging design; b) production that adds value, including use of existing materials in the community for fibers, dyes, weaving and design according to the combined skill and ability of weaving groups in the community, the process of product creation using imported materials and the supplementation of cloth products; c) use of production in commercial markets, including advertizing of goods by shop sale in similar areas to the community, the creation of cotton cloth business of the Phu Thai ethnic group and the creation of markets for indigenous woven products. This also includes online sale in cooperation with educational institutes and the government sector.

\section{Discussion}

\subsection{The Background of Indigenous Cotton Cloth Products of the Phu Thai Ethnic Group}

The six communities studied in this research have been established in Thailand for many years following the immigration of Phu Thai people from Laos. The research team considers the relocation of these Phu Thai people to have also brought various cultural aspects into Thailand. This corresponds with the cultural diffusion theory of 
Niyapan Wannasiri (1997, pp. 94-96), which states that social factors cause the adaptation of behavior and knowledge. Transmission of culture is achieved through study of other cultures, relationships and inter-cultural marriage, participation in religious ceremonies and immigration as a result of social dangers such as war or natural disasters.

The researchers believe that the creation of weaving groups caused changes to the community lifestyle but also created income and culture. This is in agreement with the conclusions of Sirirat Kankaeng (2006, pp. 177-180), which state that not all weaving groups create their own structured organizations and stipulate the roles of their members. Groups that achieve success, organize their own structure, have values and develop themselves. Groups whose members show minimal cooperation do not achieve the same levels of success, as they lack philosophy and objectives.

\subsection{The Current Conditions of and Problems with the Production of Indigenous Cotton Cloth Products of the Phu Thai Ethnic Group}

There are six stages of product transformation: a) data collection; b) product transformation; c) sewing; d) adornment; e) checks; f) packaging. These stages and the various problems that they are associated with correspond to the findings of Angsika Noppalee (2004, pp. 125-133), who studied the factors of business success in community weaving groups of Southern Isan. The research found that those groups who achieved success carried out production according to the following factors: management, human resources and community. These groups also had high levels of administration and leadership. The groups had good levels of production management, marketing management, financial management, labor and member participation. Levels of interaction were average. Groups with limited success were found to have average levels of the aforementioned factors and low levels of interaction.

There are three areas of business network. The first area is the network for raw materials. The second area is the network of basic cloth sale. The third area is the network of product sale at market fairs. This corresponds to the research of Sarangsee Kaewpijit (2008, p. 212), which concerned the local folk wisdom in the production of silk in Pak Thong Chai District, Nakhon Ratchasima for the development of community goods. This research found that development in marketing was a way to promote the production of silk products from local folk wisdom so that it was developed as a business. This also involved the skill of the locals in producing silk products that were part of the community identity. For this reason, there must be development of silk to meet consumer requirements and promotion of marketing, so that the production can be used as a way to increase community income and improve the local way of life. The skill and delicacy of silk products domestically and internationally are in high demand. The target markets are abroad and in Bangkok and the development of the silk business and silk products requires design and production of patterns and styles of products. Additionally, there must be planning for the development of pattern production, use of natural dyes, use of community-made silk and efficient production.

Regarding the problems with indigenous cloth weaving among the Phu Thai ethnic group, the research team found that all problems in all processes can be solved. This agrees with the work of Jirote Dangsagoon (2004, pp. 99-100), which concerned folk wisdom and the development of community economy. Dangsagoon concluded that folk wisdom and the development of the economy come from the following factors: a) existing maintenance of culture, customs and local wisdom in the area of the community economy; b) the level of sufficiency in community lifestyle, generosity and teamwork; c) cooperation and strengthening of the community economy; d) things linking production potential and marketing; e) family and community as dependable production organizations for the economy that can create income and reputation. These things reveal the relationship between folk wisdom and the development of the community economy.

\subsection{The Integration of Creative Economic Concepts in the Development of Products in Order to Create Added Economic Value}

The first stage of the suggested model, creativity, highlights a number of recommendations for the product design process. These findings correspond to the work of Woraporn Pairatwet (2006, pp. 94-97), which found the following results concerning the production and economic supply factors of the hand-woven cotton cloth industry in Chiang Mai: a) regarding natural resources in hand-woven cotton cloth industry, there was a lack of materials in the production of white cloth products, the fiber sizes were inconsistent and imported cloth from abroad was expensive; b) regarding the production technology in hand-woven cotton cloth industry, there were a number of confusing production steps, there was a lack of production design and standards; c) regarding human resources, weavers were selected with a high skill and individual expertise from their inheritance and education; d) regarding designers, corporate networks were found to create patterns and various colours. Some groups had 
their own designers but businessmen who did not belong to a group would create their own designs, affecting the variety; e) regarding infrastructure, it was found that corporate networks had a suitable infrastructure, with the use of production technology.

The second stage of the suggested model, investment, identifies ways in which to create added economic value. The findings correspond to the research of Leandra Spangler (1978), which concerned a method of dying Batik cloth in Africa. Spangler found that cultural understanding in other art forms can be used in education to assist the teaching of African art. Spangler produced six lessons for a summer development workshop to highlight this notion: 'African stereotypes, African culture, African textile dyeing processes, traditional West African art forms, tie-dye and batik, and relationships among shape, space, pattern, and color' (Spangler, 1978, Abstract).

The third stage of the suggested model, commercialization, suggested ways for the continuation of investment in creative production and is linked to the findings of Pranom Kianthong (2008). Kianthong studied the Mud-Mee cloth business networks of the Tai-Puan community in Lopburi Province, Thailand. The results found that internal and external factors enable the weaving process to continue and the community to adapt to the modern economic market. Internal factors included agricultural lifestyle and external factors included capitalist development. Additionally, Rungrot Pipatanamongkon (2000) suggested that family industries produce the basic products of silk and cotton cloth. The production sale for these groups is decreasing because there is an increase in market competition that causes the need for adaptation of quality and product form in order to compete.

\section{References}

Dangsagoon, J. (2004). Local Wisdom and Development of Community Economy: A Case Study of Stone Polished Bronzewares. Padittrolakan Community, Chatujak District, Bangkok Metropolitan, Bangkok: Chandrakasem Rajabhat University.

Kaewpijit, S. (2008). Local Wisdom in the Production of Thongchai Embroidered Silk for the Development of Standard Community Products. Maha Sarakham: Mahasarakham University.

Kankaeng, S. (2006). Cultural Organizations of Silk Weaving Groups in Maha Sarakham Province. Mahasarakham: Mahasarakham University.

Kianthong, P. (2008). Dynamics and Adaptation of the Creation of Mud-Mee Weaving Business Networks in the Tai-Puan Community. Lopburi Province, Maha Sarakham: Mahasarakham University.

Mantamgarn, U. (1984). Fan Palm Leaves and Products from Palm Leaves. Bangkok: Thammasat University.

Noppalee, A. (2004). Factors for Success of Community Weaving Group Businesses in Central Isan. Maha Sarakham, Mahasarakham University.

Pairatwet, W. (2006). Study of Competition Potential for the Hand-Woven Cotton Cloth Industry in Chiang Mai. Bangkok: Chulalongkorn University.

Panlamjiag, K., \& Saengduean, S. (2011). The Management of Creative Knowledge for the Society and Creative Economy in the Teaching of Bachelor Education. Bangkok: Rajamangala University of Technology Thanyaburi.

Pipatanamongkon, R. (2000). Study of Problems with the Market of Silk Weaving Factories: A Case Study of State Enterprise Weaving Factories in City District. Roi-Et Province, Maha Sarakham: Mahasarakham University.

Spangler, L. (1978). Patterns in tie-Dye and Batik from West Africa: An Instructional Unit for Eighth and Ninth Grade Art. Education Resources Information Center, 1978. Retrieved June 4, 2007, from http://www.erice.ed.gov/ERICWewPortal/Home.portal?_hfpb= truepageLbel=reco

Wannasiri, N. (1997). Humanity, Society and Culture. Bangkok: Kasetsart University.

\section{Copyrights}

Copyright for this article is retained by the author(s), with first publication rights granted to the journal.

This is an open-access article distributed under the terms and conditions of the Creative Commons Attribution license (http://creativecommons.org/licenses/by/3.0/). 